\title{
Evaluation of Water Diffusion Mechanism on Mechanical Properties of Polypropylene Composites
}

\author{
Oluwayomi Peter Balogun $(\mathrm{D}),{ }^{1,2}$ Adeolu Adesoji Adediran $(\mathrm{D})^{3}$ \\ Joseph Ajibade Omotoyinbo $\mathbb{D}^{2},{ }^{2}$ Kenneth Kanayo Alaneme $\mathbb{B},{ }^{2,4}$ \\ and Isiaka Oluwole Oladele $\mathbb{D i D}^{2}$ \\ ${ }^{1}$ Prototype Engineering Development Institute (PEDI), PMB 5025, Ilesha, Osun State, Nigeria \\ ${ }^{2}$ Department of Metallurgical and Materials Engineering, Federal University of Technology, Akure, PMB 704, Akure, \\ Ondo State, Nigeria \\ ${ }^{3}$ Department of Mechanical Engineering, Landmark University, Omu-Aran PMB 1001, Kwara State, Nigeria \\ ${ }^{4}$ Centre for Nanoengineering and Tribocorrosion, School of Mining, Metallurgy, and Chemical Engineering, \\ University of Johannesburg, South Africa
}

Correspondence should be addressed to Oluwayomi Peter Balogun; yomdass@yahoo.com and Adeolu Adesoji Adediran; adediran.adeolu@lmu.edu.ng

Received 17 August 2020; Revised 24 September 2020; Accepted 29 September 2020; Published 19 October 2020

Academic Editor: Marta Fernández-García

Copyright (C) 2020 Oluwayomi Peter Balogun et al. This is an open access article distributed under the Creative Commons Attribution License, which permits unrestricted use, distribution, and reproduction in any medium, provided the original work is properly cited.

\begin{abstract}
This study evaluates the water diffusion mechanism on mechanical properties of polypropylene reinforced composites. Compounding of the composites into sheets was carried out using the compression moulding techniques by incorporating varying weight percentage of fibers and polypropylene. Mechanical properties of the composites were assessed according to ASTM standards, while the composite fracture surface was examined using a scanning electron microscope. The water absorption behaviour and diffusion mechanisms on mechanical properties of fabricated composites were analysed using a water immersion test and the Fickian diffusion model. The results show that mechanical properties of all polypropylene reinforced composites under dry condition was higher than wet condition. The composites reinforced with 7 wt.\% $(\mathrm{KOH}$ and $\mathrm{NaOH})$ fibers follow a consistent trend and gave the highest tensile strength and tensile modulus in comparison with pure PP (polypropylene). Addition of fibers into the polypropylene matrix gradually decreases composites impact strength with exception to $3 \mathrm{wt} . \%$ and $5 \mathrm{wt} . \%$ composites. The hardness properties of reinforced composites were steadily increased as the fiber loading increases which signify strong fiber-matrix bonding. The percentage of water absorbed for all reinforced composites increased as the fiber weight increases and slowly flattened off after 10 days of saturation. The morphological study revealed fiber pullout and delamination of reinforced composites attributed to poor fiber-matrix adhesion amount to water intake. The diffusion transport mechanism of polypropylene composites was observed to obey the Fickian diffusion model.
\end{abstract}

\section{Introduction}

Nowadays, the development of novel polymer composites derived from natural and synthetic fibers has experienced a remarkable progress in both composites industries and domestic use [1]. Natural fiber derivatives from wood, hemp, and kenaf are progressively replacing conservative fiberglass and nonrecyclable fibers attributed to their unique mechanical properties, ecofriendly, abundant, low-cost, and renewable [2]. They are extensively used in composite fabrication, manufacturing industries, and domestic use [3-5]. Natural fiber is hydrophilic in nature and witnessed major setbacks in polymeric composites due to the presence of their hydroxyl groups such as lignin, cellulose, and waxes [6]. These hydroxyl groups and other fiber constituents contribute to their hydrophilic nature and effortlessly absorbed moisture, making them difficult to adhere strongly with the matrix interface. However, in recent years, efforts have 
been made on exploring the use of chemical treatments to eliminate these hydroxyl groups by dissolution of hydrogen bonds within the cellulose compounds [7]. This targets the reduction in fiber moisture absorption and subsequently promotes good adhesion between the matrix and reinforcements $[8,9]$. Meanwhile, water absorption uptake in fiberreinforced polymeric composites leads to poor stress transfer, polymer degradation, and dimensional instability and contributes harmful effects to composite structural reliability and performance $[10,11]$. The movement of water molecules inside composite materials occurs by diffusion mechanism. Fick's law is one of the models used to predict quite a number of diffusion mechanisms of polymer composites due to its simplicity [12]. Generally, under Fickian's laws, diffusion of water molecules in composites is considered by three categories of mechanisms [13] including the flow of water molecules within the microcracks of the polymer chains, transportation of water molecules through the capillary into cavities and voids created within the fiber-matrix interface $[14,15]$, and finally the overall effect of swelling of the composites which spreads within the microvoids of the composite matrix [15]. Several exertions have been investigated to predict water absorption intake on polypropylene composites using various techniques [16]. Mat-Shayuti et al. [17] studied the effect of water absorption characteristics on polypropylene reinforced with polycarbonate and concluded that composites established a transitional absorption value between polypropylene and polycarbonate. Similarly, a decrease in water absorption of reinforced composites was observed as related to unreinforced polymer. Hernandez-Diaz et al. [18] evaluated the impact strength and water absorption characteristic on newspaper recycled polypropylene composites. The result suggested that reduction in impact properties was observed, while the water absorption uptake increases with lignocellulose contents, and the diffusion mechanism of composites was observed to follow the Fickian law. Boris et al. [19] examined the water adsorption characteristic and diffusion mechanism of plaster Rhecktophyllum camerunense fiber composites. The result revealed that the initial period kinetics adsorption increases steadily and begins to undergo saturation after 28 hours and subsequently noticed that the moisture diffusion mechanism does not follow Fick's law. Wang et al. [20] studied the influence of water absorption and hygrothermal behaviour on mechanical properties of polypropylene incorporated with wood powder. The results concluded that mechanical properties such as tensile strength and modulus were reduced compared with dry specimen. The diffusion mechanism of water molecules in composites was found to gradually increased and obey the Fickian law. Stamboulis and Baillie [21] examined the effect of environmental degradation of flax fiber and reported that moisture absorption of Duralin flax fiber was reduced compared with untreated fiber with considerable effect on mechanical properties. The water uptake of flax fiber was $30 \%$ lower that of green flax fiber. Thus, it is imperative to study the hydration phenomena of polypropylene reinforced with Entada mannii fiber using the Fickian model to predict water uptake and improve the bonding structures with the matrix. However, Entada mannii plant is a liana plant and climber that entangles the trunk on their host. The plant stem is structured with arrangements of fiber bundles within the bark stem [22]. The fibers are twined around the bark stem, which enhanced the bending and torsional strength for the plant system. Equally, another important feature of this plant is the supply of water through capillary techniques to the upper part of the plant system. Hence, this study is to explore this desideratum. Thus, to encourage the large use of novel polymer composites in industrial and domestic use, it is crucial to examine the effects of moisture absorption on mechanical properties of polypropylenebased composites. Similarly, it is vital to study the mechanism of water absorption by considering the kinetics of moisture diffusion and their capillary transport of water molecules into the polymer-matrix interface to produce robust composite materials. Therefore, the aim of the research work is to evaluate the water diffusion mechanisms and water absorption characteristics on mechanical properties of polypropylene composites.

\section{Materials and Methods}

2.1. Materials. The materials utilized for this research are polypropylene homopolymer density of $0.91 \mathrm{~g} / \mathrm{cm}^{3}$ and melt flow rate of $250^{\circ} \mathrm{C} / 2.10 \mathrm{~kg} ; 500 \mathrm{~g}$ of maleic anhydride polypropylene MAAP granules was supplied by Safripol, South Africa; $500 \mathrm{~kg}$ of Entada mannii fibers was gotten from Ondo state, Nigeria. Teflon sheets were used as releasing agent, and distilled water was used as the aqueous medium for the immersion test.

\subsection{Methods}

2.2.1. Extraction of Fibers. Fibers were extracted from the fiber bundles by the conventional hand stripping method. The extracted fibers were collected and sundried for 2 days, after which they were separated from foreign materials and dried in an oven at $65^{\circ} \mathrm{C}$ for 24 hours to properly remove fiber moisture. The Entada mannii fiber plant and hand stripped fibers are presented in Figures 1(a) and 1(b). The composites fabrication is as presented in Figure 2 and Table 1 shows the composites percentage variation and codes.

2.2.2. Treatment of the Extracted Fibers. The untreated fiber was placed in a water bath containing $5 \% \mathrm{KOH}$ and $\mathrm{NaOH}$ solutions and treated at $50^{\circ} \mathrm{C}$ for 4 hours. The treated fibers obtained were delignified and later washed with distilled water to remove the remaining alkaline present within the fiber. The drying of the fiber was carried out in an oven at $65^{\circ} \mathrm{C}$ for $24 \mathrm{hrs}$ and afterwards wrapped in plastic bags to evade moisture absorption from the environment. The composition fiber constituents, lignin, hemicellulose, and cellulose presented in Table 2, were determined using the neutral detergent fiber method as presented by Balogun et al. [23].

2.3. Composite Production. The $\mathrm{KOH}-$ and $\mathrm{NaOH}$-treated fibers weighed $1 \%, 3 \%, 5 \%$, and $7 \%$ were chopped into $3 \mathrm{~mm}$ length and mixed with polypropylene and 5\% MAPP compatibilizers. These combinations were later dried in an 


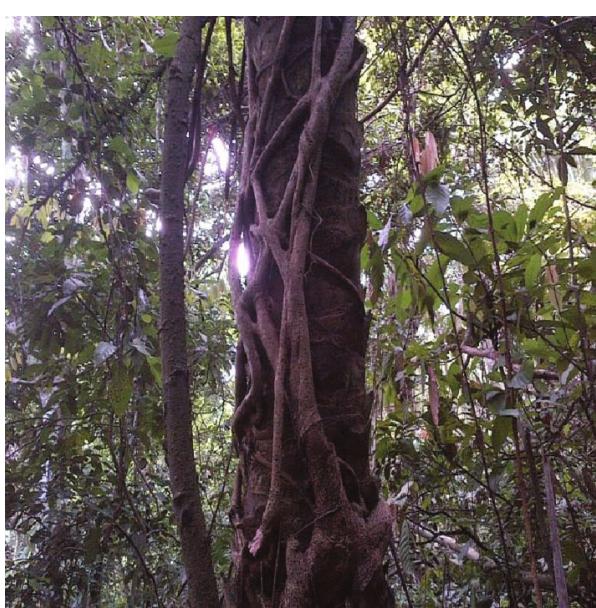

(a)

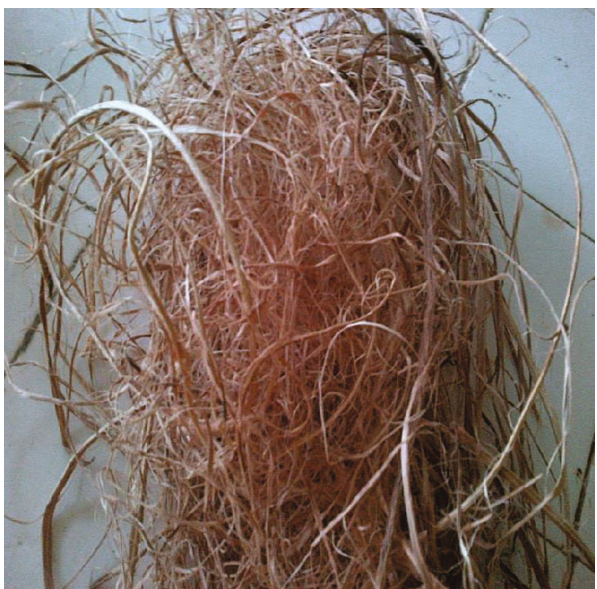

(b)

FIgURE 1: (a) Distribution of Entada mannii fibers. (b) Strands of Entada mannii fibers.

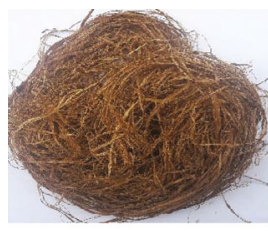

(a)

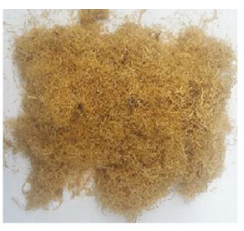

(b)

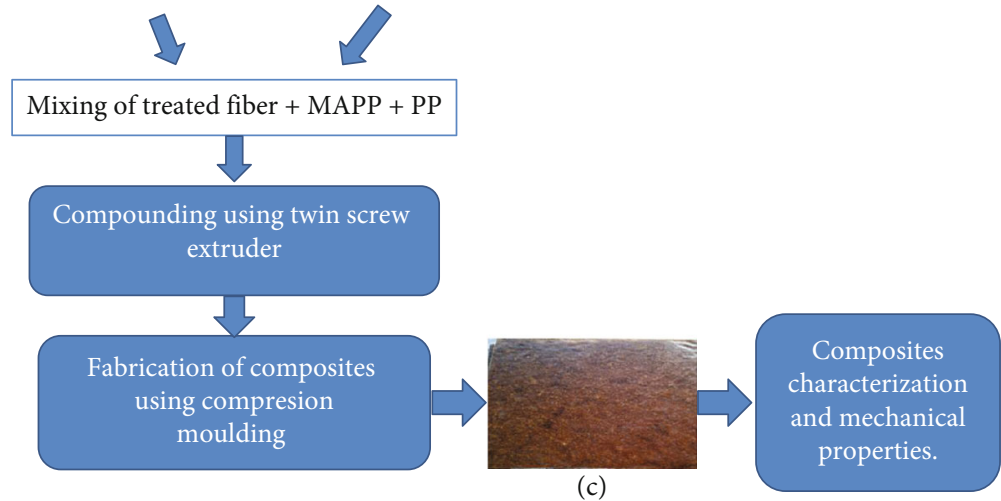

(c)

FIgURE 2: Fabrication of composites. (a) Raw Entada mannii fiber. (b) Crushed Entada mannii fiber. (c) Fabricated composite.

TABLE 1: Composites percentage variations and codes.

\begin{tabular}{lcc}
\hline \multirow{2}{*}{ Composite variations (KOH and $\mathrm{NaOH}$ fibers) } & \multicolumn{2}{c}{ Codes } \\
& $\mathrm{KOH}$ & $\mathrm{NaOH}$ \\
\hline 1 wt. (\%) & $\mathrm{KA} 1$ & $\mathrm{NB} 1$ \\
3 wt. (\%) & $\mathrm{KA} 2$ & $\mathrm{NB} 2$ \\
5 wt. (\%) & $\mathrm{KA} 3$ & $\mathrm{NB} 3$ \\
7 wt. (\%) & KA4 & $\mathrm{NB} 4$ \\
Pure PP & PP & \\
\hline
\end{tabular}

air-circulated oven at $65^{\circ} \mathrm{C}$ for 4 hours to avoid moisture absorption before extruded using Twin-Screw extruder model TSJ-20B supplied by Nanjing Tengda Equipment limited, China. During the extrusion process, temperature was regulated to avoid fiber degradation $\left(130^{\circ} \mathrm{C}-190^{\circ} \mathrm{C}\right)$ max- imum temperature zones with die temperature $\left(240-260^{\circ} \mathrm{C}\right)$ and screw speed of $120 \mathrm{rev} / \mathrm{min}$. Afterwards, the extrudate was transferred to an industrial granulation to reduce the fiber composites to dimensions of $2 \mathrm{~mm}$ to $4 \mathrm{~mm}$, respectively. The granulated specimen was fabricated into sheets dimensioning $150 \mathrm{~mm} \times 150 \mathrm{~mm} \times 4 \mathrm{~mm}$ using compression moulding machine of pressure of $150 \mathrm{MPa}$ at $190^{\circ} \mathrm{C}$ for 12 minutes to achieve the even distribution of the fiber in composite matrix. The developed composites were stored in an oven at $60^{\circ} \mathrm{C}$ to avoid moisture contacts.

2.4. Determination of the Mechanical Properties of Composites. The tensile test of both dry and wet composites specimen was carried out on the Instron tensile testing machine according to ASTM $680 \mathrm{D}$ [24]. The Instron machine with load cell of $15 \mathrm{kN}$ at speed of $5 \mathrm{~mm} / \mathrm{min}$. The test was 
TABLE 2: Fiber constituents after chemical treatments.

\begin{tabular}{lccccc}
\hline Samples & Lignin & $\mathrm{pH}$ & \% ash content & \% cellulose & \% hemicellulose \\
\hline KOH-treated fibers & 10.55 & 6.73 & 5.9 & 67.87 & 31.36 \\
NaOH-treated fibers & 9.29 & 7.45 & 4.35 & 54.79 & 40.88 \\
\hline
\end{tabular}

carried out to determine both the tensile properties and modulus of elasticity of the composites. Six repeated samples of $150 \mathrm{~mm} \times 20 \mathrm{~mm} \times 4 \mathrm{~mm}$ were tested, and the average value obtained was recorded. The composite impact test was performed on the Izod impact testing machine according to ISO 180 standard [25]. Composite specimen of dimension 10 $\mathrm{mm} \times 5 \mathrm{~mm} \times 2 \mathrm{~mm}$ notch was loaded on the impact testing machine and struck by a pendulum head of $7.5 \mathrm{~J}$ at a speed of $3.5 \mathrm{~m} / \mathrm{s}$. Six samples were performed concurrently, and the average values were recorded. The hardness properties of the composites were performed on the Brinell hardness testing machine with an applied load of $10 \mathrm{~N}$ and measured 10 indentations on each specimen. The average indentation was calculated, and the average was recorded.

2.5. SEM of the Composites. The influence of water absorption on the specimen morphology was characterized by the scanning electron microscope model JEOL JSM-7600F. Samples obtained from the tensile test was used to study the effect of moisture intake. The specimens were positioned in a vacuum compartment and layered with 100 A iridium JEOL sputter.

2.6. Water Absorption Test. Water absorption test was carried out in accordance with ASTM D570 [26]. Specimens obtained from tensile tests were placed in an oven at $65^{\circ} \mathrm{C}$ for 2 days. The specimen after drying was weighed, and the initial value was documented. The soaking was done in purified water at $25^{\circ} \mathrm{C}$, and the sample was later removed from the moist environment and cleaned using a dried duster and repeatedly weighed afterwards for period of 10 days. The specimen was weighed periodically for $24 \mathrm{~h}$ intervals and up to $216 \mathrm{~h}$ until the specimen reached saturation peak. Conversely, the water absorption test for the polymer was calculated using the equation (1).

$$
W(\%)=\frac{W t-W 0}{W o} \times 100 .
$$

Where $W$ is percent water absorption, and $W o$ and $W t$ are the ovendry weight and the weight of the specimen after time $t$, respectively.

2.7. Kinetics of Diffusion Mechanism of Polymer Composites. The diffusion mechanisms of water uptake were calculated using the kinetic parameter slope $(n)$ and intercept $(k)$ by using the following equations (2) and (3) [27].

$$
\frac{M_{T}}{M \infty}=K T^{n}
$$

$$
\log \frac{M_{T}}{M \infty}=\log (k)+n \log (T)
$$

Where $M_{T}$ is water absorption at time $T, M \infty$ is water absorption at saturation point, $k$ is a constant related to the polymer network structure, and $n$ is the release exponent which determines the type of diffusion.

\section{Results and Discussion}

3.1. Influence Moisture Absorption on Tensile Behaviour Composites. The tensile properties of polypropylene composites reinforced with Entada mannii fibers and pure PP are presented in Figure 3. It is obvious that the tensile strength of all developed composites is higher than pure PP. It is equally observed that KA4 and NB4 (7 wt.\% $\mathrm{KOH}$ and $\mathrm{NaOH}$ ) reinforced composites had the highest tensile strength of 82.3 MPa and 74.45 $\mathrm{MPa}$, respectively, and significantly increased by $58 \%$ and $55 \%$ with respect to pure PP. This improvement is ascribed to the effects of alkaline treatments which enhanced the removal of fiber components such as wax, hemicellulose, and lignin causing poor fiber-matrix interfacial bonding. Additionally, effective stress distribution from the matrix-reinforcement improved the interfacial bonding strength of the fabricated composites [28]. The tensile modulus of fiber-reinforced composites and pure PP is presented in Figure 4. It is observed that tensile modulus decreases with an increase in fiber loading. This trend was noticeable for all the reinforced composites attributed to relatively poor fiber-matrix interfacial adhesion causing the reinforced polypropylene composites to absorb water than unfilled counterparts [29]. It is also observed that the presence of microcracks generated within the composite interface causes swelling stress by activating the capillary mechanism through the matrix interface. However, these fibers absorbed the higher moisture content due to the hydrophobic nature and subsequently attacked the bonding properties of the polymer composites.

Furthermore, Table 3 presented the percentage reduction in the tensile strength of all composites under wet and dry conditions. It is observed that the tensile strength of all composites under wet condition was significantly reduced compared with dry specimen. Among the fabricated composites, both KA4 and NB4 had the highest percentage reduction in tensile strength compared with other counterparts. This is credited to an increase in fiber volume causing poor fiber-matrix bonding by creating interfacial stress and higher diffusion of moisture into composites under wet conditions. Apparently, moisture intake affects weak interfacial adhesions between fiber and matrix resulting in low tensile values of the composite [30]. The proportion of wetness increases owing to the presence of hydroxyl group in Entada 


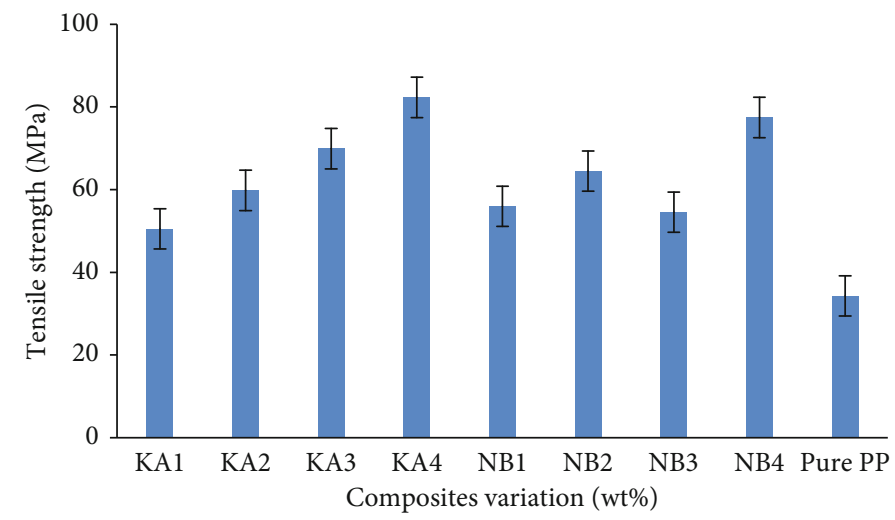

FIgURE 3: Comparison of tensile strength of reinforced composites and pure PP.

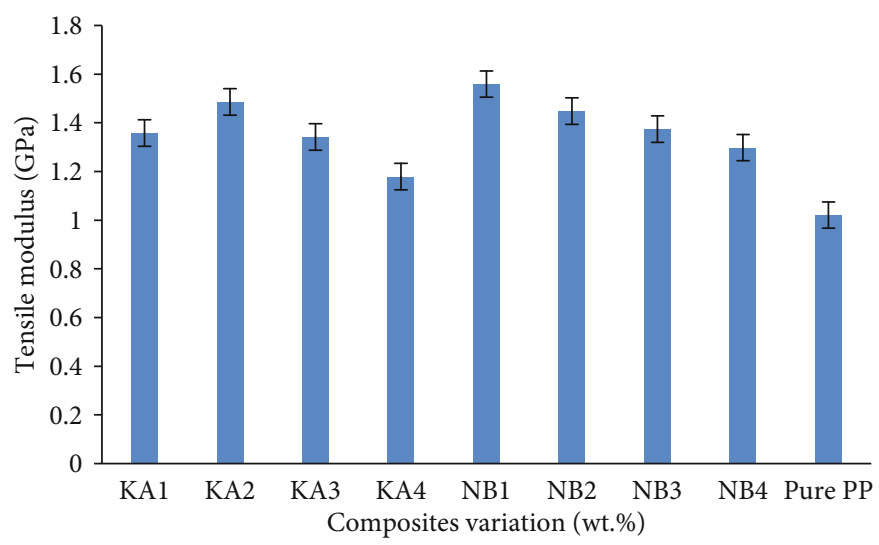

Figure 4: Comparison of tensile modulus reinforced composites and pure PP.

mannii fiber which leads to higher affinity for moisture absorption and seemingly resulted in reduction in bonding strength compared to pure PP. Generally, as the fiber volume increases, the tensile behaviour of composites is expected to decline due to an increase in the amount of water absorption thereby causing the shear stress and increases the swelling of the cellulose fiber [31].

3.2. Effect of Water Absorption Properties on Impact Behaviour of Composites. The impact strength of polypropylene composites reinforced with Entada mannii fibers and pure PP is presented in Figure 5. Experimental studies show that the impact strength of all reinforced composites gradually decreases as the fiber weight increases with exception to KA2 and NB3 composites, respectively. As the fiber weight increases, reduction in impact strength is ascribed poor fiber-matrix interfacial bonding within the composites. On the other hand, both KA2 and NB3 had the best impact strength as compared with other counterparts. This same trend was observed by KA3 and KA4, respectively, with an increase in fiber loading. The improvement is largely attributed to the uniform distribution of the fibers with the matrix interface which facilitates composites ability to withstand shear stress compared to pure PP. Table 4 illustrates the percentage reduction in the impact strength of reinforced composites and pure PP under dry and wet conditions. The results show that the impact strength of all reinforced composites was observed to drop under wet condition as compared with dry condition. On the average, KA4 and NB4 composites had a higher affinity to absorbed moisture and experienced a higher percentage reduction in impact strength as compared with other counterparts. This implied that an increase in fiber weight of the composites is attributed to a higher affinity to absorb moisture than pure PP [32]. Equally, the presence of voids created within the composite interface allows water molecules to effortlessly penetrate into the fiber-matrix interface.

3.3. Hardness Properties of the Composites. The hardness properties of polypropylene reinforced with Entada mannii fibers and pure PP are presented in Figure 6. The results revealed that the hardness properties of all composites increase with fiber weight percent. Among the fabricated composites, KA4 composites and NB4 composites had the best hardness values increase by $48 \%$ and $44 \%$ as compared with pure PP. The increase in hardness values is ascribed to the even distribution of the fibers in the matrix interface which increases the composite stiffness. However, this improvement moderates the composites and impinges the crack growth when load is applied. The comparison results of the hardness test under wet and dry conditions are presented in Table 5. The results indicated that under wet 
TABLE 3: Comparison of tensile strength and modulus of elasticity of polypropylene composites under wet and dry conditions.

\begin{tabular}{lccccc}
\hline $\begin{array}{l}\text { Composites } \\
\text { codes }\end{array}$ & \multicolumn{2}{c}{$\begin{array}{c}\text { Dry specimen } \\
\text { Tensile strength } \\
(\mathrm{MPa})\end{array}$} & $\begin{array}{c}\text { Tensile Modulus } \\
(\mathrm{GPa})\end{array}$ & $\begin{array}{c}\text { Tensile strength } \\
(\mathrm{MPa})\end{array}$ & $\begin{array}{c}\text { Tensile Modulus } \\
(\mathrm{GPa})\end{array}$ \\
\hline KA1 & 50.52 & 1.558 & 45.1 & 1.122 & 10.7 \\
KA2 & 59.81 & 1.486 & 53.03 & 1.235 & 11.3 \\
KA3 & 69.90 & 1.342 & 65.9 & 1.356 & 14.3 \\
KA4 & 82.30 & 1.179 & 68.35 & 1.456 & 17.0 \\
NB1 & 55.98 & 1.559 & 50.05 & 1.095 & 10.0 \\
NB2 & 64.47 & 1.448 & 56.38 & 1.197 & 12.5 \\
NB3 & 54.53 & 1.374 & 44.22 & 1.298 & 1.134 \\
NB4 & 77.45 & 1.298 & 60.23 & 1.9 \\
PPP & 34.3 & 1.051 & 32.5 & 1.102 & 19.1 \\
\hline
\end{tabular}

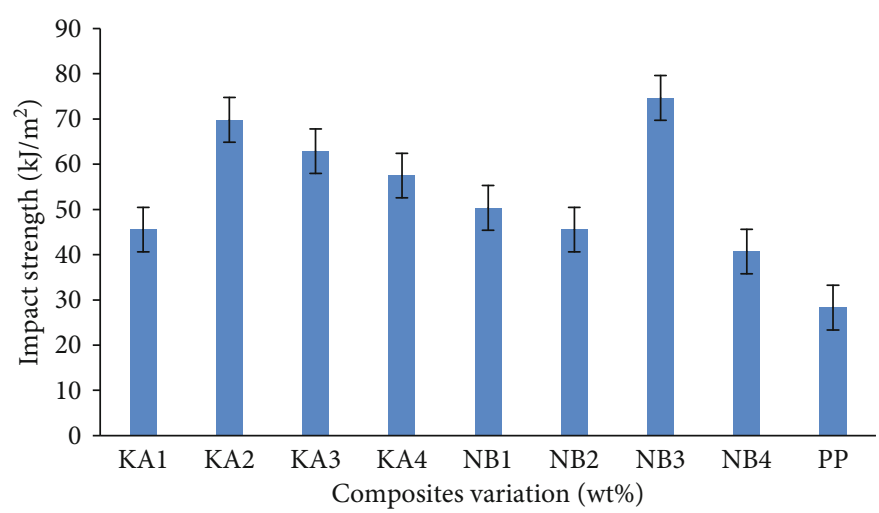

Figure 5: Comparison of impact strength of $\mathrm{KOH}-$ and $\mathrm{NaOH}$-treated fiber-reinforced composites and pure PP.

TABLE 4: Comparison of Impact strength of polypropylene composites under wet and dry conditions.

\begin{tabular}{lccc}
\hline Composites & $\begin{array}{c}\text { Dry } \\
\text { specimen } \\
\text { Impact } \\
\text { strength } \\
\left(\mathrm{kJ} / \mathrm{m}^{2}\right)\end{array}$ & $\begin{array}{c}\text { Wet } \\
\text { specimen } \\
\text { Impact } \\
\text { strength } \\
\left(\mathrm{kJ} / \mathrm{m}^{2}\right)\end{array}$ & $\begin{array}{c}\text { \% reduction in } \\
\text { impact strength } \\
\left(\mathrm{kJ} / \mathrm{m}^{2}\right)\end{array}$ \\
\hline KA1 & 45.52 & 44.93 & 7.8 \\
KA2 & 69.81 & 65.32 & 6.4 \\
KA3 & 62.90 & 57.61 & 5.2 \\
KA4 & 57.50 & 50.23 & 12.6 \\
NB1 & 50.30 & 46.73 & 7.1 \\
NB2 & 45.53 & 42.44 & 6.7 \\
NB3 & 74.67 & 70.22 & 5.9 \\
NB4 & 40.70 & 35.30 & 13.2 \\
PPP & 28.30 & 27.12 & 4.2 \\
\hline
\end{tabular}

condition, slight reduction in hardness properties was observed for all the fabricated composites as compared with dry condition. However, the percentage reduction in hardness properties was higher with KA4 and NB3, respectively, compared with dry specimen. Equally, the percentage reduc- tion in hardness properties of $\mathrm{KOH}$ polypropylene composites was improved than $\mathrm{NaOH}$ polypropylene composites owing to the effective removal of wax and impurities. This also enhanced the physicochemical properties and interfacial adhesion between the fiber and matrix and prevents water to penetrate into the composites.

3.4. SEM of the Composites after Water Absorption. The SEM analysis of polypropylene composites reinforced with $\mathrm{KOH}$ and $\mathrm{NaOH}$ fibers under wet conditions is presented in Figures 7 and 8. With respect to Figure 7, the result revealed that the fractured surface of KA1, KA2, and KA4 composites was characterized by fiber pullout and fiber debonding, respectively, with higher moisture uptake until saturation point is achieved. Apparently, higher fiber pullout was observed with KA4 composites with $7 \%$ fiber weight absorbed moisture due to feeble bonds that exist within the composites which create cracks and composites delamination [31-33]. As a result of continuous swelling of composites with fiber weight increases, composites subjected to mechanical loading were observed to fracture at lower values as shown in Table 3. Consequently, as the composites are continuously exposed to the moisture, it is observed that higher cellulose in the fiber absorbed water and undergo matrix yielding due to the expansion of shear stress at the 


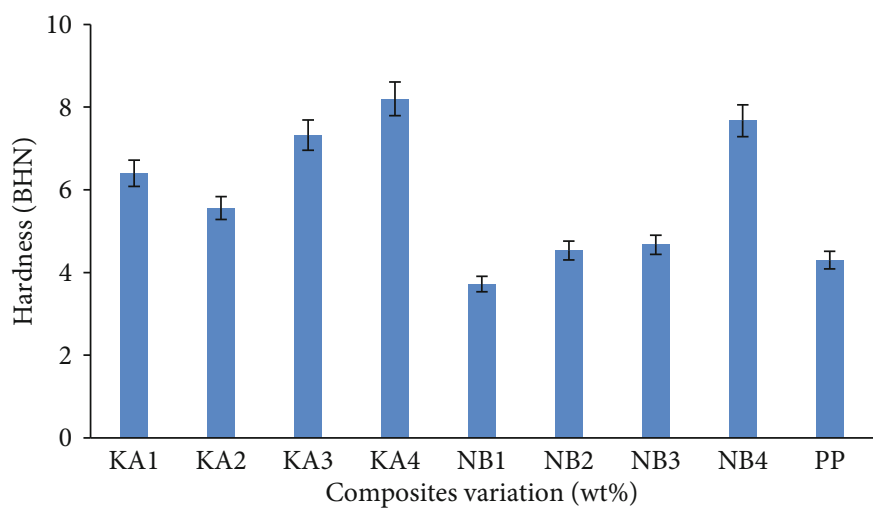

FIgUre 6: Comparison of Hardness properties of $\mathrm{KOH}$ and $\mathrm{NaOH}$ treated fiber-reinforced composites and pure PP.

TABlE 5: Comparison of Hardness properties of polypropylene composites under wet and dry conditions.

\begin{tabular}{lccc}
\hline $\begin{array}{l}\text { Composites } \\
\text { codes }\end{array}$ & $\begin{array}{c}\text { Dry specimen } \\
\text { Hardness } \\
\text { properties } \\
\text { (BHN) }\end{array}$ & $\begin{array}{c}\text { Wet specimen } \\
\text { Hardness } \\
\text { properties(BHN) }\end{array}$ & $\begin{array}{c}\text { \% reduction in } \\
\text { impact strength }\end{array}$ \\
\hline KA1 & 6.40 & 4.90 & 23.4 \\
KA2 & 5.56 & 4.39 & 21.0 \\
KA3 & 7.32 & 6.10 & 16.6 \\
KA4 & 10.2 & 7.52 & 26.3 \\
NB1 & 3.72 & 2.78 & 25.3 \\
NB2 & 4.53 & 3.44 & 24.1 \\
NB3 & 4.67 & 3.26 & 30.2 \\
NB4 & 7.67 & 5.67 & 20.1 \\
PPP & 4.3 & 3.80 & 11.6 \\
\hline
\end{tabular}

fiber-matrix boundary interface as shown in Figure 8. The continuous exposure of $\mathrm{NB} 1$ and NB4 composites to moist environment damages the structural integrity and increases fiber pullout and composites delamination [34, 35]. This explained the lower mechanical properties of the wet samples as compared with the dry specimen in Table 3. However, homogeneous surface was observed with NB2 fiberreinforced composites as compared with other counterparts.

3.5. Water Absorption Behaviour of Composites. The water absorption plot of $\mathrm{KOH}$-treated fiber-reinforced composites and pure with respect to time is presented in Figure 9. Evidently, the amount of moisture absorbed for all composites increases with an increase in weight percent and time attaining the saturation peak level. It is observed that KA4 had the highest weight gain under the wet condition followed by KA2 and least with the pure PP. This could be credited to an increase in fiber weight percent and reduction in fibermatrix bonding which triggered the behaviour of reinforced polymer composites to absorbed water than the pure PP counterparts [36]. Additionally, moisture absorption of the fiber after treatment increases with the $\mathrm{KOH}$-treated com- posites created pores and damages the fiber surface by exposing the fiber surface area compared to pure PP. Similar work was studied by [37], on the impact of banana fiber treatment on mechanical epoxy composite. Their findings show that after the alkali treatment of the banana fiber composites, moisture absorption increases with fiber contents. Hence, this suggested that the Entada mannii fiber-reinforced composites are more hydrophilic in comparison to pure $\mathrm{PP}$ which is hydrophobic. Conversely, the addition of $5 \mathrm{wt} . \%$ MAPP compatibilizers reduces the fiber contact with water ascribed to chemical bonding between MAPP and cellulose [38]. It is evident that the water absorption increase with immersion time for all the composites and attains equilibrium after 10 days $(216 \mathrm{~h})$, referred to as the water absorption saturation point.

The water absorption characteristics of the polypropylene composites reinforced with $\mathrm{NaOH}$ treated and pure $\mathrm{PP}$ are presented in Figure 10. Obviously, the rate of moisture absorption of $\mathrm{NaOH}$ treated composites was intensified with increasing fiber loading as compared with pure PP. It is observed that NB4, NB3, and NB2 composites experienced the highest moisture uptake owing to higher cellulose content that has a higher affinity to absorbed moisture as compared with pure PP. However, this implied that as the fiber weight increases, Entada mannii fibers have prospects to absorbed moisture contents after chemical treatment causing incomplete dissolution of hemicellulose and intensify cellulose contents $[39,40]$. Additionally, after treatment fiber surface is exposed, fibrillar structure was altered causing poor fibermatrix interfacial adhesion under wet conditions as compared to pure PP [41]. A saturation point was attained after 10 days of immersion for both $\mathrm{NaOH}$ treated and pure PP.

3.6. Water Diffusion Mechanism in Composites. The comparison of $\log \left(M_{T} / M \infty\right)$ versus $\log (T)$ of the $\mathrm{KOH}$ - and $\mathrm{NaOH}$-treated fibers composites with slope $(n)$ of composite diffusion mechanism is presented in Figures 11 and 12. Accordingly, during the diffusion process, moisture absorption trend fitting into the Fickian diffusion mechanism curve as presented in Figures 11 and 12, the process could be considered as the Fickian diffusion process [42]. Equally, while the amount of flow of the water molecules 


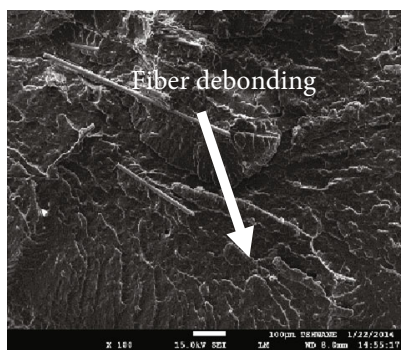

(a)

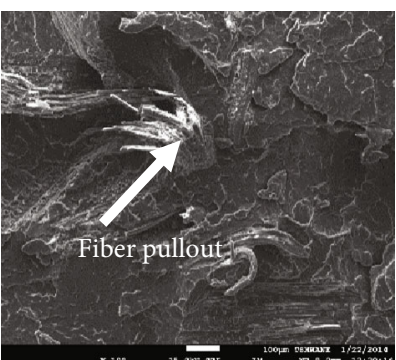

(b)

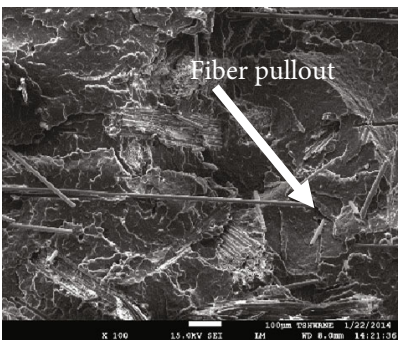

(c)

Figure 7: SEM images of the KA1, KA2, and KA4 KOH-treated fiber composites.

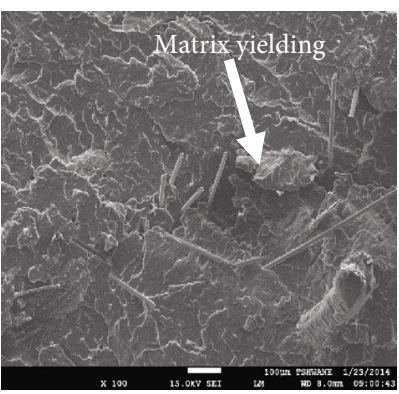

(a)

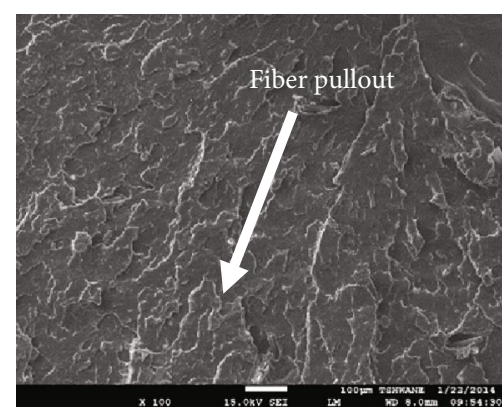

(b)

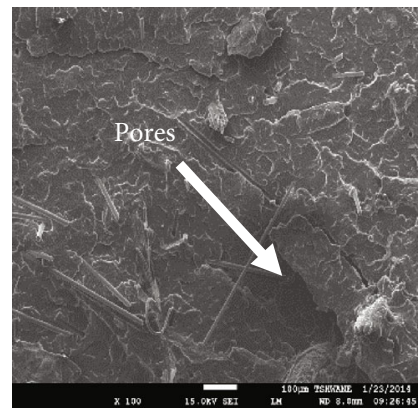

(c)

Figure 8: SEM images of NB1, NB2, and NB4 NaOH-treated composites.

in the composites is considerably lesser than the composite sectional movement, the Fickian diffusion mechanism (Case I) is said to be established [43]. During the diffusion process, the slope of the mechanism determined $n=0.5$ is not time dependent, and hence, the composite diffusion rate is exceptionally obtained [43,44]. Subsequently, for the Case II diffusion mechanism, the level of $n=1.0$ which specifies the diffusion procedure is faster than the moder- ation route ( $R_{\text {diff }} \mathfrak{E} R_{\text {mod }}$, system measured by relaxation), this process described the improvement of the border between the enlarged external portion and the internal slippery core of the composite $[44,45]$. The borderline progresses at a steady speed, and the core reduces in dimension pending a stable saturation level is accomplished within the composite [46]. $0.5<n<1.0$ indicated the non-Fickian (anomalous) diffusion mechanism of the 


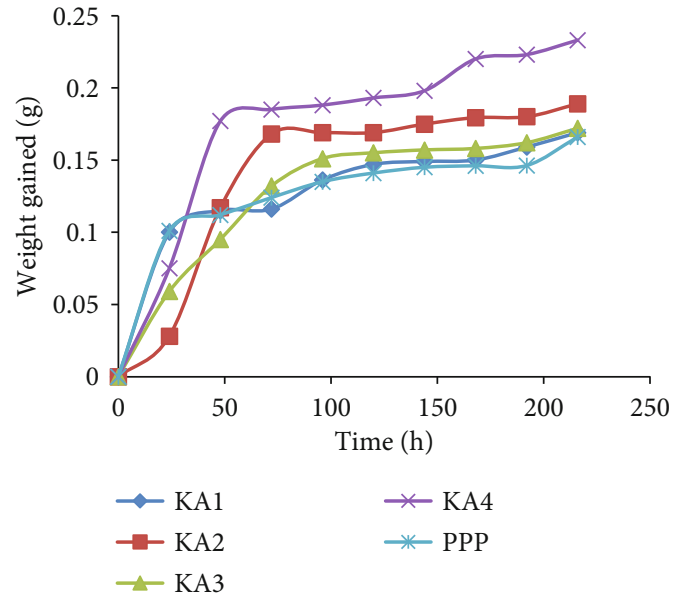

FIGURE 9: Water absorption tests for $\mathrm{KOH}$-treated reinforced composites and the pure PP.

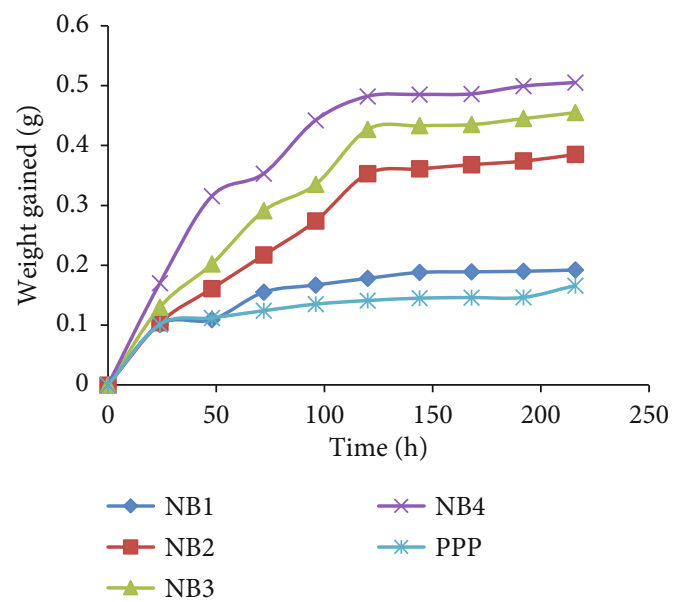

Figure 10: Water absorption tests for $\mathrm{NaOH}$-treated composites and the pure PP.

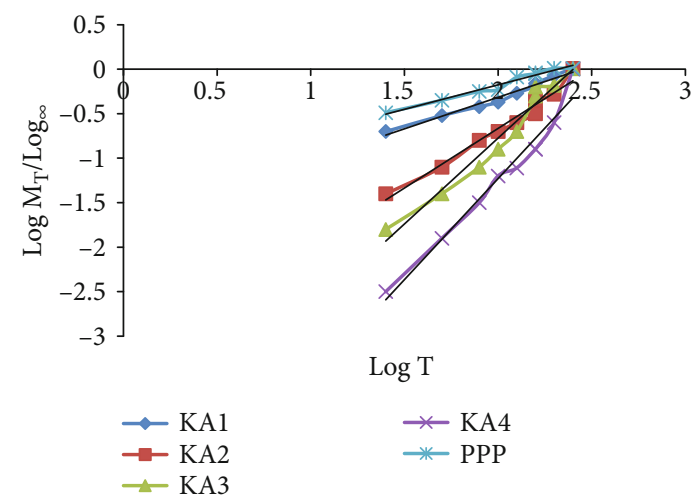

FIGURE 11: Diffusion mechanism curve for KOH-treated composites and the pure PP.

composites, which defines conditions where the diffusion and relaxation proportions are equal $\left(R_{\text {diff }} \approx R_{\text {relax }}\right)$. Consequently, a transitional performance between the Fickian and non-Fickian diffusion was observed [36]. Super Case
II the kinetic of the diffusion mechanism of the composites is obtained when the value of $n>1$. Additionally, when $n<0.5$, the potential of attaining moisture flow rate is much lesser that the polymer chain reduction rate, and thus, the process obeyed a less Fickian mechanism. However, KA1 and NB1 polymer composites in Figures 10 and 11 display a transitional characteristic mechanism between the Fickian and non-Fickian diffusion, notably for the diffusion movement and polymeric division relaxation point. Consequently, it is noted that as the weight fraction of moisture uptake increases, the fiber volume fraction increases payable to the elimination of fiber components that covered the fiber interface and subsequently increases the cellulose content [47]. Conversely, the diffusion coefficients $(n)$ of KA2, KA3, NB4, and KA4, respectively, had their slopes approximately 1.0 or higher. This specified that the diffusion mechanism obeyed the super Case II, while the rate of water molecules penetrates the composites exceeded the relation process. Hence, it is evident that as the water absorption rate increases, the value of the diffusion exponent also increases. It can therefore be said that the volume of moisture absorbed by the composites is proportional to the diffusion exponent $(n)$ and hence influences the diffusion transport mechanism [48].

The transport mechanisms of all the polymeric composites are presented in Table 6, while values of slope $n$ and intercept $k$ calculated from equations (2) and (3) are determined from the graph in Figures 11 and 12, respectively. Similarly, the means of water delivery mechanism of the Entada mannii composite is presented in Table 7. Of all the composites produced, it is evident that values of the diffusion coefficient $(n)$ for both NB2 and PPP composites in Table 7 are considerably less than 0.5 which means that the transport mechanism is less Fickian. Thus, the rate of water dispersion is considered to reduce beneath polymer chain relaxation [49]. The water absorption arrangement of the composites exhibited Fickian behaviour, and on the other hand, as the immersion time increases, composites were observed to follow a nonFickian behaviour. The value of $n$ for the NB3-treated fiber-reinforced composite was found to be 0.5 . This indicates that the flow of dispersion of water molecules in treated composite is much lesser than sectional movement due to the alkaline treatment of the fiber [50].

\section{Conclusions}

The influence and effects of water absorption characteristic on polypropylene composites reinforced with Entada mannii were investigated. The results show that

(i) The tensile strength and tensile modulus of reinforced composites and pure PP were considerably improved as the fiber loading increases. The $7 \mathrm{wt} . \%$ composites (KA4 and NB4) fiber were observed to follow a consistent trend and had the highest tensile strength and tensile modulus as compared with pure PP 


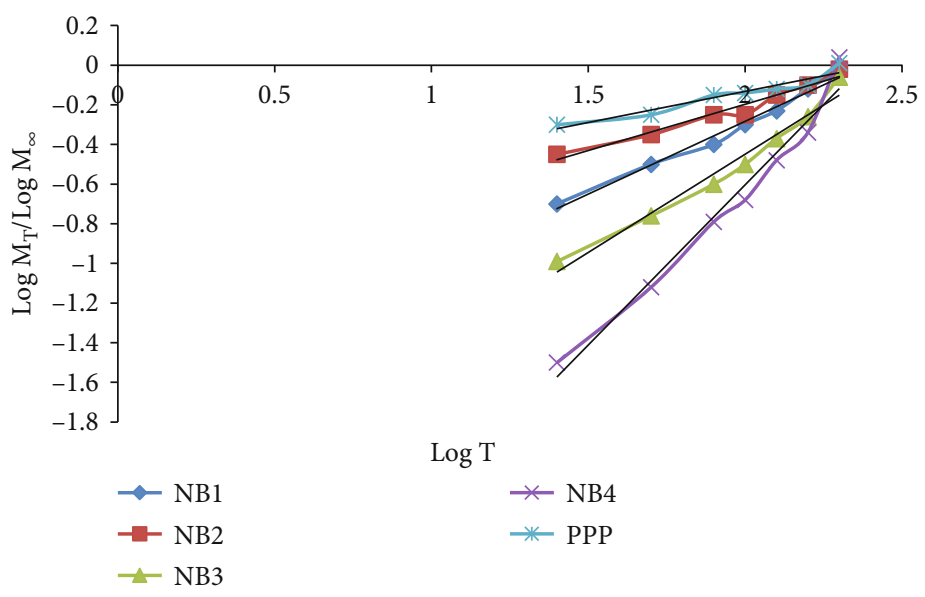

Figure 12: Diffusion mechanism curve for $\mathrm{NaOH}$-treated composites and the pure PP.

TABLE 6: Moisture contents values obtained for the composites.

\begin{tabular}{lccr}
\hline Composition & Slope $(n)$ & Intercept $(k)$ & $R^{2}$ \\
\hline Pure PP & 0.313 & 0.759 & 0.921 \\
KA1 & 0.707 & 1.730 & 0.976 \\
KA2 & 1.334 & 3.346 & 0.971 \\
KA3 & 1.929 & 4.631 & 0.964 \\
KA4 & 2.269 & 5.763 & 0.962 \\
NB1 & 0.734 & 1.752 & 0.985 \\
NB2 & 0.466 & 1.130 & 0.960 \\
NB3 & 0.502 & 2.433 & 0.970 \\
NB4 & 1.616 & 3.835 & 0.921 \\
\hline
\end{tabular}

TABLE 7: Water transport mechanism for produced composites.

\begin{tabular}{lcccc}
\hline Type of transport & Slope $(n)$ & Time dependence & Composites & \% range of water absorptions \\
\hline Less Fickian diffusion & $n<0.5$ & $\mathrm{t}^{-1 / 2}$ & NB2, pure PP & $0-0.6$ \\
Fickian diffusion & $n=0.5$ & $\mathrm{t}^{1 / 2}$ & NB3 & $1.70-2.80$ \\
Non-Fickian (anomalous diffusion) & $0.5<n<1.0$ & $\mathrm{t}^{\mathrm{n}-1}$ & KA1, NB1 & $3.5-7.8$ \\
Case II transport independent & $n=1.0$ & Time & KA2, NB4 & 2.89 \\
Super Case II transport & $n>1.0$ & $\mathrm{t}^{\mathrm{n}-1}$ & KA2, KA3, KA4, NB4 & $3.5-7.8$ \\
\hline
\end{tabular}

(ii) The addition of Entada mannii fiber reduces the impact strength of the developed composites with exception KA2 (3 wt.\% KOH) and NB3 (5 wt.\% $\mathrm{NaOH}$ ), respectively. A progressive increase in hardness properties of the fabricated composites with the addition of Entada mannii fiber as compared with pure PP. However, KA4 and NB4 composites had the highest hardness values increase by $48 \%$ and $44 \%$ as compared with pure PP

(iii) SEM analysis revealed that polypropylene reinforced composites under wet condition was characterized by fiber pullout, debonding, and composites delamination in comparison with pure PP (iv) As the fiber loading increases, the amount of water absorption also increases for all the reinforced composites and pure PP composites. Among the fabricated composites, $7 \mathrm{wt} . \%(\mathrm{NaOH}$ and $\mathrm{KOH})$ had the highest value of water absorption percentage compared with pure PP. On the other hand, with less free volume in the pure PP, the rate of water penetration into the composites is negligible as related with the reinforced polypropylene composites

(v) All the composites followed the forecasted Fick's law where the amount of water absorbed increases linearly and progressively level off after saturation level is reached 


\section{Data Availability}

The data used to support the findings of this study are included within the article.

\section{Conflicts of Interest}

The authors declare that they have no conflicts of interest.

\section{Acknowledgments}

The authors wish to recognize African Materials Science and Engineering Network (AMSEN), Regional Initiative in Science Education (RISE), Science Initiative Group (SIG) for their sponsorship, and Prof. Peter Olubambi and Prof. C. M Khoathane for their collaborative support during my visit to South Africa. Adeolu Adesoji Adediran acknowledges the Landmark University Centre for Research, Innovation, and Development (LUCRID) for their support.

\section{References}

[1] K. L. Pickering, G. W. Beckermann, S. N. Alam, and N. J. Foreman, "Optimising industrial hemp fibre for composites," Composites: Part A, vol. 38, no. 2, pp. 461-468, 2007.

[2] T. Singh, C. I. Pruncu, B. Gangil, V. Singh, and G. Fekete, "Comparative performance assessment of pineapple and Kevlar fibers based friction composites," Journal of materials research and technology, vol. 9, no. 2, pp. 1491-1499, 2020.

[3] T. Singh, P. Pattnaik, C. I. Pruncu, A. Tiwari, and G. Fekete, "Selection of natural fibers based brake friction composites using hybrid ELECTRE-entropy optimization technique," Polymer Testing, vol. 89, article 106614, 2020.

[4] J. Gassan, "Effects of corona discharge and UV treatment on the properties of jute-fibre epoxy composites," Composites Science and Technology, vol. 60, no. 15, pp. 2857-2863, 2000.

[5] M. W. Richardson, T. J. Madera-Santana, and J. Hague, "Natural fibre composites- the potential for the Asian markets," Progress Rubber Plastic Technology, vol. 14, pp. 174-188, 1998.

[6] T. Singh, B. Gangil, A. Patnaik, S. Kumar, A. Rishiraj, and G. Fekete, "Physico-mechanical, thermal and dynamic mechanical behaviour of natural-synthetic fiber reinforced vinylester based homogenous and functionally graded composites," Materials Research Express, vol. 6, no. 2, 2019.

[7] M. Z. Rong, M. Q. Zhang, Y. Liu, G. C. Yang, and H. M. Zeng, "The effect of fiber treatment on the mechanical properties of unidirectional sisal-reinforced epoxy composites," Composites Science and Technology, vol. 61, no. 10, pp. 1437-1447, 2001.

[8] M. M. Kabir, H. Wang, K. T. Lau, and F. Cardona, "Effects of chemical treatments on hemp fibre structure," Applied Surface Science, vol. 276, pp. 13-23, 2013.

[9] O. M. L. Asumani, R. G. Reid, and R. Paskaramoorthy, "The effects of alkali-silane treatment on the tensile and flexural properties of short fibre non-woven kenaf reinforced polypropylene composites," Composites Part A: Applied Science and Manufacturing, vol. 43, no. 9, pp. 1431-1440, 2012.

[10] D. Verma, P. C. Gope, M. K. Maheshwari, and R. K. Sharma, "Bagasse fiber composites-a review," Journal of Materials and Environment Science, vol. 3, no. 6, pp. 1079-1092, 2012.

[11] S. Panthapulakkal and M. Sain, "Studies on the water absorption properties of short hemp-glass fiber hybrid polypropylene composites," Journal of Composite Materials, vol. 41, no. 15, pp. 1871-1883, 2016.

[12] M. K. T. D. Brito, W. R. G. D. Santos, B. R. D. B. Correia et al., "Moisture Absorption in Polymer Composites Reinforced with Vegetable Fiber: A Three-Dimensional Investigation via Langmuir Model," Polymers, vol. 11, no. 11, p. 1847, 2019.

[13] J. Wang, W. Wu, and Z. Lin, "Kinetics and thermodynamics of the water sorption of 2-hydroxyethyl methacrylate/styrene copolymer hydrogels," Journal of Applied Polymer Science, vol. 109, no. 5, pp. 3018-3023, 2008.

[14] M. H. Shirangi and B. Michel, "Mechanism of moisture diffusion, hygroscopic swelling, and adhesion degradation in epoxy molding compounds," Moisture Sensitivity of Plastic Packages of IC Devices, pp. 29-69, 2010.

[15] A. Shakeri and A. Ghasemian, "Water absorption and thickness swelling behavior of polypropylene reinforced with hybrid recycled newspaper and glass fiber," Applied Composite Materials, vol. 17, no. 2, pp. 183-193, 2010.

[16] A. A. R. Abdalla, S. S. Mohd, A. Khalina, M. Megat, and M. P. Hamdan, "Water absorption behaviour of kenaf reinforced unsaturated polyester composites and its influence on their mechanical properties," Journal of Science and Technology, vol. 18, no. 2, pp. 433-440, 2010.

[17] M. Z. Abdullah, M. S. Mat-Shayut, and P. S. M. Megat-Yuso, "Water absorption properties and morphology of Polypropylene/ Polycarbonate/Polypropylene-graft-Maleic anhydride blends," Asian Journal of Scientific Research, vol. 6, no. 2, pp. 167-176, 2013.

[18] D. Hernández-Díaz, R. Villar-Ribera, F. X. Espinach, F. Julián, V. Hernández-Abad, and M. Delgado-Aguilar, "Impact Properties and Water Uptake Behavior of Old Newspaper Recycled Fibers-Reinforced Polypropylene Composites," Materials, vol. 13, no. 5, p. 1079, 2020.

[19] N. Boris, "Study of the diffusion behavior of water vapor sorption in natural fiber composite: plaster/Rhecktophyllum camerunense," MOJ Applied Bionics and Biomechanics, vol. 3, no. 1, 2019.

[20] W. Wang, X. Guo, D. Zhao, L. Liu, R. Zhang, and J. Yu, "Water Absorption and Hygrothermal Aging Behavior of WoodPolypropylene Composites," Polymers, vol. 12, no. 4, p. 782, 2020.

[21] A. Stamboulis, "A composites based on polypropylene matrix," Applied Composite Materials, vol. 7, no. 5/6, pp. 273-294, 2000.

[22] O. P. Balogun, J. A. Omotoyinbo, K. K. Alaneme, and A. A. Adediran, "Physical and mechanical properties of Entada mannii particulates reinforced composites," Heliyon, vol. 6, no. 6 , article e04157, 2020.

[23] O. P. Balogun, J. A. Omotoyinbo, and K. K. Alaneme, "Structural characteristics, thermal degradation behaviour, and tensile properties of hand extracted Entada Mannii fibres," Journal of Physical Science, vol. 27, pp. 89-102, 2016.

[24] V. Chaudhary, P. K. Bajpai, and S. Maheshwari, "Studies on mechanical and morphological characterization of developed jute/hemp/flax reinforced hybrid composites for structural applications," Journal of Natural Fibers, vol. 15, no. 1, pp. 80-97, 2017.

[25] A. Baby, S. Y. Nayak, S. S. Heckadka, S. Purohit, K. K. Bhagat, and L. G. Thomas, "Mechanical and morphological characterization of carbonized egg-shell fillers/Borassus fibre reinforced polyester hybrid composites," Materials research Express, vol. 6 , no. 10, 2019. 
[26] K. K. Alaneme, S. R. Oke, and J. A. Omotoyinbo, "Water absorption characteristics of polyester matrix composites reinforced with oil palm ash and oil palm fibre," Usak University Journal of Materials Sciences, vol. 2, no. 2, pp. 109-356, 2013.

[27] O. O. Daramola, S. Olajide, and O. S. Akintayo, "Water absorption characteristics of Epoxy matrix composites reinforced with green silica particles," Leonardo Electronic Journal of Practices and Technologies, vol. 32, pp. 215-232, 2018.

[28] G. T. Mahesha, S. B. Satish, K. M. Vijaya, and K. S. Bhat, "Preparation of Unidirectional Grewia Serrulata Fiber-Reinforced Polyester Composites and Evaluation of Tensile and Flexural Properties," Journal of Natural Fibers, vol. 13, no. 5, pp. 547554, 2016.

[29] A. Cárdenas, W. Argüelles-Monal, F. M. Goycoolea, I. Higuera-Ciapara, and C. Peniche, "Diffusion through membranes of the polyelectrolyte complex of chitosan and alginate," Macromol Bioscience, vol. 3, no. 10, pp. 535-539, 2003.

[30] S. Keshk, W. Suwinarti, and K. Sameshima, "Physicochemical characterization of different treatment sequences on kenaf bast fiber," Carbohydrate Polymers, vol. 65, no. 2, pp. 202-206, 2006.

[31] A. Athijayamani, M. Thiruchitrambalam, U. Natarajan, and B. Pazhanivel, "Effect of moisture absorption on the mechanical properties of randomly oriented natural fibers/polyester hybrid composite," Materials Science and Engineering A, vol. 517, no. 1-2, pp. 344-353, 2009.

[32] P. K. Kushwaha and R. Kumar, "Studies on Water Absorption of Bamboo-Polyester Composites: Effect of Silane Treatment of Mercerized Bamboo," Polymer-Plastics Technology and Engineering, vol. 49, no. 1, pp. 45-52, 2009.

[33] H. DHAKAL, Z. ZHANG, and M. RICHARDSON, "Effect of Water Absorption on the Mechanical Properties of Hemp Fibre Reinforced Unsaturated Polyester Composites," Composites Science and Technology, vol. 67, no. 7-8, pp. 16741683, 2007.

[34] E. Muñoz and J. A. García-Manrique, "Water absorption behaviour and its effect on the mechanical properties of flax fibre reinforced bioepoxy composites," International Journal of Polymer Science, vol. 2015, 10 pages, 2015.

[35] H. N. Dhakal, Z. Y. Zhang, N. Bennett, A. Lopez-Arraiza, and F. J. Vallejo, "Effects of water immersion ageing on the mechanical properties of flax and jute fibre biocomposites evaluated by nanoindentation and flexural testing," Journal of Composite Materials, vol. 48, no. 11, pp. 1399-1406, 2013.

[36] J. Suwanprateeb, "Calcium carbonate filled polyethylene: correlation of hardness and yield stress," Composites Part A: Applied Science and Manufacturing, vol. 31, no. 4, pp. 353359, 2000.

[37] N. Venkateshwaran, A. E. Perumal, and D. Arunsundaranayagam, "Fiber surface treatment and its effect on mechanical and visco-elastic behaviour of banana/epoxy composite," Materials and Design, vol. 47, pp. 151-159, 2013.

[38] J. P. López, J. Gironès, J. A. Méndez et al., "Stone-ground wood pulp-reinforced polypropylene composites: water uptake and thermal properties," BioResources, vol. 7, no. 4, 2012.

[39] D. N. Saheb and J. P. Jog, "Natural fiber polymer composites: a review," Advances in Polymer Technology, vol. 18, no. 4, pp. 351-363, 1999.

[40] Q. T. H. Shubhra, A. K. M. M. Alam, and M. A. Quaiyyum, "Mechanical properties of polypropylene composites," Journal of Thermoplastic Composite Materials, vol. 26, no. 3, pp. 362391, 2011.

[41] A. K. Bledzki and O. Faruk, "Creep and impact properties of wood fibre-polypropylene composites: influence of temperature and moisture content," Composites Science and Technology, vol. 64, no. 5, pp. 693-700, 2004.

[42] H. Deng, C. T. Reynolds, N. O. Cabrera, N.-M. Barkoula, B. Alcock, and T. Peijs, "The water absorption behaviour of all-polypropylene composites and its effect on mechanical properties," Composites Part B: Engineering, vol. 41, no. 4, pp. $268-275,2010$.

[43] G. D. Magdalena and O. Jadwiga, "Mechanism of water diffusion into non cross linked and ionically cross-linked chitosan membranes," Chair of Physical Chemistry and Physicochemistry of Polymer Progress on Chemistry and Application of Chitin, vol. 17, pp. 63-70, 2012.

[44] K. V. R. Rao, K. P. Devi, and P. Buri, "Cellulose Matrices for Zero-Order Release of Soluble Drugs," Drug Development and Industrial Pharmacy, vol. 14, no. 15-17, pp. 2299-2320, 2008.

[45] D. L. Munday and P. J. Cox, "Compressed xanthan and karaya gum matrices: hydration, erosion and drug release mechanisms," International Journal of Pharmaceutics, vol. 203, no. 1-2, pp. 179-192, 2000.

[46] J. Crank, The mathematics of diffusion, Clarendon Press, Oxford, 1975.

[47] S. Mishra, J. B. Naik, and Y. P. Patil, "Studies on swelling properties of wood/polymer composites based on agro-waste and novolac," Advances in Polymer Technology, vol. 23, no. 1, pp. 46-50, 2004.

[48] A. Espert, F. Vilaplana, and S. Karlsson, "Comparison of water absorption in natural cellulosic fibres from wood and one-year crops in polypropylene composites and its influence on their mechanical properties," Composites Part A: Applied Science and Manufacturing, vol. 35, no. 11, pp. 1267-1276, 2004.

[49] B. C. Patel, S. K. Acharya, and D. Mishra, "Environmental effect of water absorption and flexural strength of red mud filled jute fiber/polymer composite," International Journal of Engineering, Science and Technology, vol. 4, no. 4, 2013.

[50] P. Upadhyaya, M. Garg, V. Kumar, and A. K. Nema, "The Effect of Water Absorption on Mechanical Properties of Wood Flour/Wheat Husk Polypropylene Hybrid Composites," Materials Sciences and Applications, vol. 3, no. 5, pp. 317-325, 2012. 